\section{Gestillte Babys essen das Frühstücksei mit}

\author{
Um einer Hühnereiweißallergie entgegenzuwirken, wird stillenden \\ Müttern eine Ei-freie Diät empfohlen. Eine randomisierte Studie \\ untersuchte, ob Menge und Art des Eigehalts der Nahrung einen \\ Einfluss auf den Eiproteingehalt in der Muttermilch hat.
}

\begin{abstract}
A ustralische Pädiater gewannen 41 stillende Frauen für eine randomisierte verblindete Cross-over-Studie. Die Mütter erhielten zwischen der 11. und 14. Laktationswoche einmal wöchentlich ein Testfrühstück, das sich jeweils nur im Eigehalt unterschied: ein Heidelbeer-Muffin mit einem ganzen, einem halben oder keinem Ei und ein Bananenmilchshake mit oder ohne rohem Ei. Die Zusammensetzung des Testfrühstücks änderte sich an jedem Untersuchungstag. Vor dem Testtag mussten sich die Frauen jeweils 48 Stunden Eifrei ernähren. Bei $80 \%$ der Fälle gelang dies vollständig, ansonsten wurden nur kleine Mengen an Ei zusammen mit an-
\end{abstract}

deren Nahrungsmitteln zugeführt. Am Testtag selbst wurde eine Milchprobe von $20 \mathrm{ml}$ vor dem Frühstück sowie 2, 4, 6 und 8 Stunden danach genommen. Um den Einfluss des Eigehalts des Frühstücks auf den Gehalt an Eiprotein in der Muttermilch zu ermitteln, wurde der Gehalt von Ovalbumin als häufigstes Eiprotein mittels ELISA bestimmt.

Die maximale Ovalbuminkonzentrekt mit der Menge an garem Ei im Frühstück: Bei einem Frühstück ohne Ei lag sie bei $0,05 \mathrm{ng} / \mathrm{ml}$, bei einem halben Ei im Muffin bei $2,24 \mathrm{ng} / \mathrm{ml}$ und bei einem Muffin mit einem ganzen Ei bei $3,16 \mathrm{ng} / \mathrm{ml}$. Entsprechend war auch die ration in der Muttermilch korrelierte di- gesamte Ovalbuminausscheidung dosisabhängig: Sie betrug $0,18 \mathrm{ng} / \mathrm{ml} / \mathrm{h}$ ohne $\mathrm{Ei}, 4,93 \mathrm{ng} / \mathrm{ml} / \mathrm{h}$ bei einem Muffin mit halbem Ei und $9,14 \mathrm{ng} / \mathrm{ml} / \mathrm{h}$ bei einem ganzen Ei. Die maximale Konzentration wie die Gesamtmenge des ausgeschiedenen Ovalbumins war nach Genuss eines rohen Eis genauso hoch wie bei einem halben Ei im Muffin. Aber: 24\% der Frauen wiesen zumindest während der 8stündigen Nachbeobachtungszeit keinerlei Ovalbumin in der Muttermilch auf.

Fazit: Bei drei Viertel der untersuchten Frauen trat Ovalbumin nach Eigenuss dosisabhängig in die Muttermilch über. $\mathrm{Ob}$ es bei den restlichen Probandinnen zu einer verzögerten oder auch zu gar keiner Albuminexkretion in der Milch kam, bleibt offen.

Palmer DJ et al. Effect of cooked and raw egg consumption on ovalbumin content of human milk: a randomized, doubleblind, cross-over trial. Clin Exp Allergy 2005; 35: 173-8

\section{Die Schnecken-Milben-Connection}

\section{Schneckenfleisch gilt aufgrund seines hohen}

Protein- und geringen Fettgehaltes als sehr gesund, allerdings kommen auch Nahrungsmittelallergien gegen Schnecken vor. Eine Arbeitsgruppe untersuchte nun die Allergene von essbaren Schnecken.

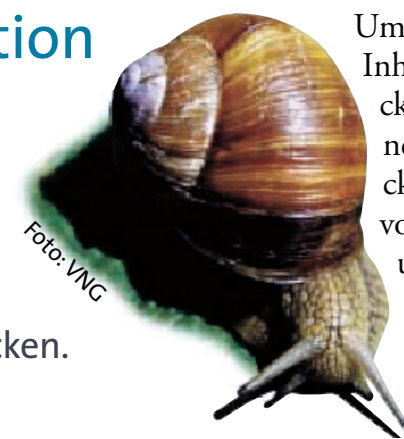

- in portugiesisch-französisches Forscherteam rekrutierte 60 Patienten mit unterschiedlichen Organmanifestationen atopischer Erkrankungen nach Schneckenverzehr, bei sechs von ihnen hatte das Molluskenfleisch Asthmaanfälle provoziert. Die Patienten wurden einem Hautpricktest mit verschiedenen essbaren Schnecken (u. a. Helix aspersa, gefleckte Weinbergschnecke) und Milbenallergenen ( $D$. pteronyssinus) unterzogen, außerdem wurden spezifisches IgE und Gesamt-IgE bestimmt.

Das Gesamt-IgE lag im Durchschnitt über $1.000 \mathrm{kU} / \mathrm{l}$. Der Pricktest war bei 44 Patienten positiv für Weinbergschnecken und bei 56 Patienten po- sitiv für Milben. Aus dem Extrakt von Helix aspersa wurden über 20 Allergene isoliert, wobei die beiden Majorallergene (Molekulargewicht $>208 \mathrm{kD}$ ) aus der Gruppe der Myosinproteine stammten. Die Schneckenextrakte (Hel a) und die Milbenextrakte (Der p) zeigten im RAST-Inhibitionstest eine starke Eigenhemmung. Die Hemmung der Bindung an Hel a durch den Der-p-Extrakt war sehr viel ausgeprägter als die Hemmung in umgekehrter Richtung. Im Immunoblot wurde eine komplette Inhibition der IgE-Bindung durch die jeweiligen homologen Extrakte erzielt. Hel a inhibierte aber nicht die Erkennung der aus $D$. pteronyssinus isolierten Proteinfraktion.
Umgekehrt wurde eine fast komplette Inhibition der IgE-Bindung an Schneckenproteine durch die Milbenproteine erzielt. Kreuzreaktionen mit Schneckenmyosin und Myosinfraktionen von Huhn, Schwein, Kaninchen, Kuh und Pferd kamen nicht vor.

Die Autoren folgern aus ihren Resultaten, dass einer Allergie gegen Weinbergschnecken meist eine vorhergehende Milbensensibilisierung zugrunde liegt. Allerdings kann eine Hel-a-Sensibilisierung auch vorkommen, ohne dass sich spezifisches Milben-IgE nachweisen lässt. Interessant für weitere Forschungen dürfte nun die Identifizierung von gemeinsamen Epitopen von Schnecken- und Milbenallergenen sein.

Fazit: Patienten mit einer Nahrungsmittelallergie gegen Weinbergschnecken sind sehr häufig auch gegen Milben sensibilisiert.

Martins LML et al. The Helix aspersa (Brown Garden Snail) allergen repertoire. Int Arch Allergy Imunol 2005; 136: 7-15 